end of the divided bone; in the circumscription of a common abscess; in the unerring accuracy with which matter takes its course to the most favourable, least dangerous situation for expulsion.

When a body, foreign to the system, makes its way to the surface, absorption (ulcerative ?) takes place in front, making a passage for its transit, adhesion (inflammatory ?), or, at all events, a process diametrically opposite, closing up the track left in transitu. The justness of proportion existing between the former and the latter are admirable. In what physiological, or, which is more germane to the matter, in what pathological process can its preponderating influence not be made manifest?

Again; the power of metastasis, or translation of morbid affection from one part or organ to another, for the purpose of its ultimate expulsion,-one of the most beautiful efforts of benevolent nature to assist her intentions has not ( $\mathrm{I}$ believe) been sufficiently made the object of reasoning and practical application, capable as it is of much curious and interesting detail, on which a more vigorous intellect than mine might $d$ well with incalculable advantage to medical practice, and lift itself into many useful and varied contemplations. But to proceed.

Thus the cumulative indisposition consequent on the derangement of organic action, from whatever cause it arise, is, by the unseen and unappreciated Autocrateia, attempted to be transferred from the general system,- to the skin, as in the exanthemata; to the extremities, as in gout, \&c.; to the joints (and skin), in rheumatism, \&c. \&c. Pursuing still farther the mazes of this intricate subject, we may see it in that congestion of mucous membranes occurring in fevers, in the depraved secretions (probably formed by synthetical depositions of their component atoms at the moment of elimination), in the expectoration of a catarrh, in the sweating stage of an ague, and in the deposition of morbid educts through the nedium of the urine.

The discerning and skilful physician ought solely to apply his art to the furtherance and fulfilment of nature's instructions, by directing such attempts to their best ends and effects. Space does not permit of my entering more fully at present into this subject, at once most intricate and of paramount importance; I trust, however, that a probable solution has been given to the question.

To what are we to attribute the overpowering weight of quackery (professional and non-professional), which in medicine, more, infinitely more, than any other study, tends to retard its onward progress, acting as a perpetual and effectual drag on the wheels of the chariot of science? The answer is formed by reflecting on the impunity with which the constitution may be trifled with, and the natural tendency of the system to recover its equilibrium. The place of pre-eminence may, then, not be awarded to that plan of treatment which does most good, but to that which does least harm. Let me conclude in the words of the illustrious Beddoes, by hoping "that we may see that art, which can rest firmly on no other foundation than a just theory of the functions of the body, rising at length to a beautiful and solid structure. Nor, however remote medicine may be at present from such perfection, do we see any reason to doubt that, by taking advantage of various and continued accessions, as they accrue to science, the same power may be acquired over the living as is at present exercised over some inanimate bodies, and that not only the cure and prevention of diseases, but the art of securing and protracting the fairest season of life, and rendering health more vigorous, will one day half realise some of the dreams of alchemy."

London, May, 1844.

\section{FUNIS PRESENTATIONS.}

\section{To the Editor of The LanceT.}

SIn,-Having found the following simple treatment successful in a recent case of presentation of the funis, and as the state of my patient when I visited her seems to me to be very similar to that of Dr. J. H. Davis's first case, related in The Lancer of the 22nd of June, I take the liberty to send you a brief account of it.
The patient was a stout woman, about twenty-five years old, and in labour for the second time. When $I$ arrived she had experienced severe pains for twelve hours, with the exception of the last two hours, the pains having subsided immediately after the discharge of the liquor amnii. I found the cord filling up the vagina and projecting a little from the external opening, the head high up, and the os uteri about half dilated.

I immediately introduced my hand and pushed the funis, spreading it about, above the shoulder and over the elbow of the child. I suffered the uterus to contract upon and to expel my hand; the head descended, at the same time, considerably. I then administered half a drachm of tincture of ergot, and in less than an hour a fine lively child was born. The mother and child did well.

Would it not generally be easy to secure the cord by pushing it over an arm or a leg of the child? I am, Sir, your most obedient servant,

Upper Tooting, July 1st.

Willitam Baingridge.

\section{F OREION DEPARTMENT.}

NEW METHOD FOR OPERATING IN HARE-LIP, BY M. MaLGatane.-(Journal de Chirurgie.)

However ably, says M. Malgaigne, the operation for hare-lip may be performed, there always remains on the median line, near the free margin of the lip, an ugly depression. Several methods have been proposed to remedy this imperfection in the operation, among which may be mentioned the operating by two curved incisions, but they have all failed in effecting the desired improvement. M. Malgaigne, therefore, proposes the following plan :The paring is commenced from above, and carried downwards. It may be done by the scissors in the same way as the ordinary operation; only when the operator has arrived so low that but a small pedicle remains, he stops. The same plan is followed on the other side. Thus two small flaps are formed, which merely adhere to the lip by their pedicle. After uniting with pins the two sides of the labial division in its entire length, except at the lower extremity, the small flaps are turned downwards and placed in juxta-position. The surgeon having formed his opinion as to the length which they ought to retain in order to form a substitute for the natural median prominence, then shapes them as he thinks fit, conserving a greater or less portion, according to the extent of the deficiency which he has to supply. He then completes the reunion by uniting the two flaps by means of a suture or two, or a very fine insect-pin. If the pin or suture is placed very near the free edge of the lip the cicatrix subsequently appears scarcely visible.

This operation has been twice performed; once by its author, a second time by M. Guersant. M. Malgaigne states that in his case the operation was perfectly successful. In M. Guersant's the median tubercle appears to have been rather too large. M. Huguier proposes to use the scalpel instead of the scissors.

TUMOURS OF THE FOETAL SURFACE OF THE PLACENTA, BY M. DANYAN.-(Journal de Chirurgie.)

M. Danyan gives two cases of this rare pathological occurrence. His patients were delivered without any difficulty. On the foetal surface of the placenta, underneath the chorion and the amnios membranes, he found a tumour, in one instance 20 centimetres (eight inches), in the other 13 centimetres (five inches) in length. The tumours, in both cases, rested on the fotal surface of the placenta, to which they adhered by vascular ramifications and by very slight adhesions. The tumours were nourished by vessels proceeding from the umbilical cord itself, and from the vascular network of the placenta. Their tissue was firm, homogenous, like scirrhous tissue, and grated underneath the scalnel. M. Danyan thinks that these productions were the result of organised sang guineous coagula. 